\title{
Role of vitamin D deficiency in type 2 diabetes: Association or coincidence?
}

\section{ABSTRACT}

Background. Vitamin D has received considerable attention for its possible role in myriad of clinical conditions especially non-communicable chronic diseases. However, it is the role in the pathogenesis of type 2 diabetes (T2DM), which has generated a lot of enthusiasm to unravel the association between the two.

Aim. To determine the prevalence of hypovitaminosis $D$ and its relation with the glycemic control in T2DM patients attending a tertiary care hospital in Kashmir. Methods. A total of 108 cases of T2DM and 101 healthy controls aged between 35-65years were investigated in this study. 25-hydroxyvitamin D (25OHD), glycosylated hemoglobin $\left(\mathrm{HbA}_{1 \mathrm{c}}\right)$ and fasting serum insulin levels were determined using standardised and automated assays. Insulin resistance (IR) and beta-cell function (B) were estimated by the homeostasis model assessment (HOMA). Results. The mean serum level of $250 \mathrm{HD}$ was significantly lower in T2DM group compared to controls $(20.55 \pm 12.27$ vs $27.62 \pm 5.32 \mathrm{ng} / \mathrm{mL} ; \mathbf{P}=0.001)$. The prevalence of hypovitaminosis $\mathrm{D}$ was significantly higher in patients with T2DM (79.5\% vs $62.7 \% ; P=0.031)$. Overall $51.1 \%$ and $28.4 \%$ patients with diabetes and $\mathbf{4 1 . 2} \%$ and $21.6 \%$ controls had vitamin D deficiency and insufficiency respectively.

Vitamin D was found to have a significantly positive association with serum fasting insulin level and HOMA-B in both cases $(P=0.019),(P=0.026)$ and controls $(P=0.022),(P=0.008)$ respectively. Prolonged gly-

Address for correspondence:

Javaıd Ahmad Bhat

Department of Endocrinology, Superspeciality Hospital

Government Medical College, Srinagar

Jammu and Kashmir, India

e-mail: javaidrasool711@gmail.com

Clinical Diabetology 2021, 10; 2: 188-194

DOI: $10.5603 /$ DK.a2021.0029

Received: 20.10 .2020

Accepted: 29.12 .2020 cemic control as determined by $\mathrm{HbA}_{1 \mathrm{c}}$ demonstrated a significant inverse correlation with vitamin $D$ level in both cases $(r=-0.225 ; P=0.035)$ and controls ( $r=-0.373 ; P=0.007)$.

Conclusion. We conclude that vitamin D deficiency (VDD) is a very common health problem and is relatively more common in patients with T2DM. There is an inversed association between vitamin $D$ and glycemic control. Vitamin D status thus appears to affect glucose homeostasis. Vitamin D screening and supplementation is a plausible way to mitigate the impact of VDD on glucose homeostasis in T2DM. (Clin Diabetol 2021; 10; 2: 188-194)

Key words: vitamin $D$ deficiency, type 2 diabetes mellitus, HOMA-IR, HOMA-B

\section{Introduction}

India, one of the fast growing economies of the world is witnessing rapid growth of diabetes cases owing to improved socioeconomic conditions and is estimated to harbor second largest diabetes population of over 77 million in 2019 in the world, which is expected to increase to 134 million in 2045 [1]. Urbanisation of lifestyle parameters and availability of affordable food items, have resulted in escalating prevalence of diabetes not only in urban dwellings but also in rural India. Like rest of India, in valley of Kashmir also, the prevalence of T2DM has shown a substantial increase from $1.89 \%$ (1.98\% in males and $1.77 \%$ in females) in 2000 , to $6.31 \%(7.15 \%$ in urban and $5.5 \%$ in rural) reported in a study published in 2015 [2,3]. This enormous increase in prevalence of diabetes mellitus (DM) and its associated complications has emerged as a major health concern in relation to increased morbidity, mortality and impaired quality of life associated with the disease [4, 5]. The epidemic 
proportions of the disease and its sequelae makes it imperative to study and find out the modifiable risk factors associated with DM and to address these factors to mitigate the impact of deleterious effects of this disease. Apart of non modifiable genetic predisposition there are many environmental factors including physical inactivity, obesity and poor dietary habits which contribute greatly to its development. However, in the recent years role of vitamin $D$, as modifiable risk factor for DM has come under careful scrutiny with studies suggesting a possible link of VDD in the pathogenesis of T2DM $[6,7]$.

Vitamin D, a fat soluble vitamin synthesized in the skin has been found to have myriad of roles in health and disease, with studies implicating its role in pathogenesis of number of chronic diseases including heart disease, autoimmune diseases, type 2 diabetes, many cancers and infectious diseases. High prevalence of DM in areas of significant VDD has generated lot of enthusiasm in unravelling the relationship between the two. The biological evidence implicating potential influence of vitamin D on insulin secretion and sensitivity include the presence of specific vitamin $D$ receptor in pancreatic cells and target organs including skeletal muscles and adipose tissues in addition to expression of 1- $\alpha$ hydroxylase enzyme in pancreatic cells [8-10].

The present study aimed to find the prevalence of VDD in patients with T2DM attending a tertiary care hospital in Srinagar, Kashmir and to examine whether 250HD has any clinically significant influence on glycemic control ( $\left.\mathrm{HbA}_{1 \mathrm{c}}\right)$ and insulin resistance (HOMA-IR) in patients with T2DM.

\section{Aims and objectives}

To determine the prevalence of hypovitaminosis D in patients with T2DM and its correlation with glycated hemoglobin $\left(\mathrm{HbA}_{1 \mathrm{C}}\right)$, a marker of glycemic control.

\section{Material and methods}

Study setting

This was a cross-sectional analytical study carried out in the Department of Medicine at Government Medical College, Srinagar after obtaining ethical clearance from institutional ethics committee. The study was carried out over a period of 18 months from November 2017 to May 2019. The study was done according to the principles expressed in the Declaration of Helsinki. A written informed consent was obtained from all the subjects, in the language that was understandable to the patient and their attendant.

\section{Study population and sample size}

A total of 108 cases of T2DM and 101 healthy controls aged between 35-65 years attending the OPD and wards of this hospital were included in the study.

\section{Inclusion criteria}

Cases: All patients aged 35-65 years with T2DM on oral anti-diabetic medication who gave informed consent.

Controls: Apparently healthy individuals aged 35-65 years who gave informed consent.

\section{Exclusion criteria}

Diabetic patients below 35 years or above 65 years, subjects with T1DM or other forms of diabetes, pregnant women, patients with chronic diseases including chronic liver disease or alanine aminotransferase $>5$ times upper reference limit, renal insufficiency (glomerular filtration rate $<30 \mathrm{~mL} / \mathrm{min}$ ), diarrhoeal or malabsorption state and tuberculosis.

\section{Methods}

25-hydroxyvitamin D level was assayed using the chemiluminescent method. $\mathrm{HbA}_{1 \mathrm{c}}$ assay was performed on the autoanalyzer (Abbott $\mathrm{GmbH} \&$ co. kg MaxPlanck-Ring 2. 65205 Wiesbaden, Germany) based on the turbidimetric inhibition immunoassay (TINIA) of hemolyzed blood samples and the hexokinase method was employed for assay of fasting plasma glucose. Enzyme-linked immunosorbent assay was used to determine the fasting serum insulin levels. Serum calcium, phosphorus, albumin and creatinine were measured using standardized and automated assays. Insulin resistance (IR) and beta-cell function (B) were estimated by the homeostasis model of assessmentinsulin resistance index (HOMA-IR) and the homeostatic model of assessment-beta (HOMA-B) respectively. Higher HOMA-IR value indicates greater IR, and a lower HOMA-B value indicates greater $\beta$-cell dysfunction.

HOMA-IR is defined as the product of fasting serum insulin $(\mu \mathrm{U} / \mathrm{mL})$ and fasting plasma glucose (FPG) $(\mathrm{mmol} / \mathrm{L})$ divided by 22.5. A score of $>4$ defined IR [11].

HOMA-B insulin secretion (IS) defined as the product of twenty and fasting insulin $(\mu \mathrm{U} / \mathrm{ml})$ divided by FPG (mmol/L) minus 3.5. A score of $<100$ defined reduced IS (B) [11].

Serum levels of 250HD were classified endocrine society guidelines into deficient $(<20 \mathrm{ng} / \mathrm{mL})$, insufficient ( $\geq 20$ to $<30 \mathrm{ng} / \mathrm{mL}$ ) and normal ( $\geq 30 \mathrm{ng} / \mathrm{mL}$ ). Subsequently, for this study, we considered all $250 \mathrm{HD}$ values of $<30 \mathrm{ng} / \mathrm{m}$ as hypovitaminosis $D$ both in cases and controls.

\section{Statistical analysis}

Data was first entered into Microsoft Excel. All statistical analyses were performed using SPSS (Statistical Package for the Social Sciences) version 25.0 software from IBM Corporation, NY, United States. The statistical 
Table 1. Demographic and laboratory parameters of cases and controls.

\begin{tabular}{|c|c|c|c|}
\hline Variable & $\begin{array}{c}\text { Cases }(n=108) \\
\text { Mean } \pm \text { SD }(95 \% \mathrm{Cl})\end{array}$ & $\begin{array}{l}\text { Controls }(n=101) \\
\text { Mean } \pm \text { SD }(95 \% \mathrm{Cl})\end{array}$ & $P$ value \\
\hline Age [Years] & $48.28 \pm 9.53(46.26-50.30)$ & $48.12 \pm 9.35(45.49-50.75)$ & 0.921 \\
\hline BMI $[\mathrm{Kg} / \mathrm{m} 2]$ & $25.60 \pm 3.59(24.84-26.36)$ & $22.58 \pm 1.78(22.08-23.08)$ & $0.000^{*}$ \\
\hline Waist to hip ratio & $1.03 \pm 0.87(0.84-1.21)$ & $0.86 \pm 0.03(0.85-0.87)$ & 1.66 \\
\hline Fasting plasma glucose [mg/dl] & $181.23 \pm 72.82(165.80-196.66)$ & $88.93 \pm 16.76(84.22-93.65)$ & $0.000^{*}$ \\
\hline Cholesterol [mg/dl] & $188.31 \pm 68.46(173.80-202.81)$ & $139.63 \pm 6.55(122.31-156.94)$ & $0.000^{*}$ \\
\hline Triglycerides [mg/dl] & $255.97 \pm 165.37(220.93-291.01)$ & $201.22 \pm 140.92(161.58-240.85)$ & $0.049 *$ \\
\hline $\mathrm{HDL}[\mathrm{mg} / \mathrm{dl}]$ & $44.26 \pm 14.87(41.10-47.41)$ & $57.51 \pm 18.56(52.29-62.72)$ & $0.000^{*}$ \\
\hline $\mathrm{LDL}[\mathrm{mg} / \mathrm{dl}]$ & $102.44 \pm 44.27(93.00-111.88)$ & $69.94 \pm 22.36(63.65-76.23)$ & $0.000^{*}$ \\
\hline Calcium [mg/dl] & $8.85 \pm 0.79(8.68-9.01)$ & $8.89 \pm 0.66(8.70-9.07)$ & 0.739 \\
\hline Phosphorus [mg/dl] & $3.59 \pm 0.98(3.38-3.80)$ & $3.28 \pm 0.65(3.10-3.47)$ & $0.044^{*}$ \\
\hline Albumin [mg/dl] & $4.15 \pm 0.63(4.02-4.29)$ & $3.98 \pm 0.61(3.80-4.15)$ & 0.110 \\
\hline Fasting insulin [IU/mL] & $12.18 \pm 10.28(10.01-14.36)$ & $7.93 \pm 4.74(6.60-9.27)$ & $0.006^{*}$ \\
\hline HOMA-IR & $5.62 \pm 6.42(4.26-6.98)$ & $1.61 \pm 0.82(1.38-1.85)$ & $0.000 *$ \\
\hline HOMA-B & $22.88 \pm 24.16(17.76-28.00)$ & $30.65 \pm 24.48(23.76-37.53)$ & $0.000 *$ \\
\hline Vitamin $D[\mathrm{ng} / \mathrm{mL}]$ & $20.55 \pm 12.26(17.95-23.14)$ & $27.61 \pm 5.32(23.30-31.92)$ & $0.001 *$ \\
\hline $\mathrm{HbA}_{1 \mathrm{C}} \%$ & $8.48 \pm 2.54(7.94-9.02)$ & $5.08 \pm 0.61(4.90-5.25)$ & $0.003^{*}$ \\
\hline Vitamin D deficiency \% [n] & $51.1(55)$ & $41.2(41)$ & 0.257 \\
\hline Vitamin D insufficiency \% [n] & $28.4(31)$ & $21.6(22)$ & 0.375 \\
\hline Hypovitaminosis D \% [n] & $79.5(86)$ & $62.8(63)$ & $0.031 *$ \\
\hline
\end{tabular}

Categorical data are shown as \%; continuous variables are shown as mean \pm standard deviation. *Significance. HDL - high density lipoproteins, LDL low density lipoproteins; $\mathrm{HbA}_{1 \mathrm{C}}$ - glycosylated hemoglobin; HOMA-IR - homeostasis model of assessment-insulin resistance index; HOMA-B - homeostasis model of assessment- beta; $\mathrm{Cl}$ - confidence interval; $\mathrm{n}$ - number of patients

techniques used for analyzing this data were independent student t-test and one-way ANOVA with multiple range tests. Wherever applicable, an appropriate nonparametric test like Mann Whitney, Kruskal Wallis and other tests were used. A P-value of less than 0.05 was considered significant.

\section{Results}

A total of 108 cases comprising of $51 \%$ male ( $n=55)$ and $49 \%$ female $(n=53)$ and age matched 101 controls comprising of $60.8 \%$ males $(n=61)$ and $39.2 \%$ females $(n=40)$, were included in this study. Demographic and laboratory characteristic of the study population is shown in the Table 1.

The mean age and BMI of cases and controls at presentation was $48.28 \pm 9.53$ years vs $48.12 \pm 9.35$ years and $25.60 \pm 3.59 \mathrm{~kg} / \mathrm{m}^{2}$ vs $22.58 \pm 1.78 \mathrm{~kg} / \mathrm{m}^{2}$ respectively. The prevalence of hypovitaminosis $D$ was significantly higher in patients of T2DM compared to controls $(79.5 \%$ vs $62.8 \% ; P=0.031)$. Overall $51.1 \%$ and $28.4 \%$ patients with diabetes and $41.2 \%$ and $21.6 \%$ of controls had VDD and insufficiency respectively. The mean serum level of $250 \mathrm{HD}$ was significantly lower in T2DM group compared to controls (20.55 \pm 12.27 vs $27.62 \pm 5.32 \mathrm{ng} / \mathrm{mL} ; \mathrm{P}=0.001)$. Fasting plasma insulin and HOMA-IR values were significantly higher in T2DM cases compared to control group $(12.18 \pm 10.28$ vs $7.93 \pm 4.74 \mathrm{mlU} / \mathrm{L} ; \mathrm{P}=0.006)$ and $(5.62 \pm 6.42 \mathrm{mg} / \mathrm{dl}$ vs $1.61 \pm 0.82 \mathrm{mg} / \mathrm{dl} ; \mathrm{P}=0.000)$. However, HOMA-B was significantly higher in control group compared to T2DM patients $(30.65 \pm 24.48$ vs $22.88 \pm 24.16 ; P=0.000)$. On sub analysis of diabetes group (Table 2), comparison of patients with good glycemic control $\left(\mathrm{HbA}_{1 \mathrm{c}}<7 \%\right)$ with those of poor glycemic control $\left(\mathrm{HbA}_{1 \mathrm{c}} \geq 7\right)$ revealed fasting insulin levels and HOMA-B were significantly higher (14.99 \pm $12.54 \mathrm{mg} / \mathrm{dl}$ vs $10.23 \pm 7.94 \mathrm{mg} / \mathrm{dl} ; \mathrm{P}=0.032$ ) and $(32.33 \pm 31.80$ vs $16.34 \pm 13.98 ; P=0.002)$ in good glycemic group compared to those in poor glycemic group. Similarly $250 \mathrm{HD}$ level was significantly higher in patients with good glycemic control $(24.69 \pm 12.17$ $\mathrm{ng} / \mathrm{mL}$ vs $17.68 \pm 11.60 \mathrm{ng} / \mathrm{mL} ; \mathrm{P}=0.008)$. The prevalence of hypovitaminosis $\mathrm{D}$ was significantly higher in patients with poor glycemic control $(88.4 \%$ vs $66.7 \%$; $P=0.013)$, with patients having significantly higher $\operatorname{VDD}(61.5 \%$ vs $36.1 \% ; P=0.019)$.

There was a significant inverse relationship between vitamin $D$ and serum fasting blood glucose in control group ( $r=-0.402 ; P=0.003$ ) (Table 3 ). While it was inversely related but not statistically significant 
Table 2. Comparative analysis of demographic characteristics and biochemical parameters in diabetic patients with good and poor glycemic control

\begin{tabular}{lccc}
\hline Variables & $\begin{array}{c}\text { Good glycemic control }(\mathbf{n}=45) \\
(95 \% \mathrm{Cl})\end{array}$ & $\begin{array}{c}\text { Poor glycemic control }(\mathbf{n}=63) \\
(95 \% \mathrm{Cl})\end{array}$ & P value \\
\hline Age [years & $47.61 \pm 9.47(44.41-50.81)$ & $48.75 \pm 9.64(46.06-51.44)$ & 0.585 \\
Fasting plasma glucose [mg/dl] & $158.53 \pm 60.07(138.20-178.85)$ & $196.94 \pm 77.17(175.46-218.43)$ & $0.014^{*}$ \\
Cholesterol [mg/dl] & $187.83 \pm 88.14(158.01-217.65)$ & $188.63 \pm 51.62(174.26-203.01)$ & 0.957 \\
Triglyceride [mg/dl] & $253.17 \pm 166.21(196.93-309.41)$ & $257.90 \pm 166.39(211.58-304.23)$ & 0.896 \\
HDL [mg/dl] & $44.03 \pm 16.50(38.44-49.61)$ & $44.42 \pm 13.80(40.58-48.26)$ & 0.904 \\
LDL [mg/dl] & $104.69 \pm 55.63(85.87-123.52)$ & $100.85 \pm 34.62(91.11-110.60)$ & 0.692 \\
Fasting insulin [IU/mL] & $14.99 \pm 12.54(10.75-19.24)$ & $10.23 \pm 7.94(8.01-12.44)$ & $0.032^{*}$ \\
HOMA-IR & $6.19 \pm 6.25(4.08-8.30)$ & $5.23 \pm 6.56(3.40-7.05)$ & 0.493 \\
HOMA-B & $32.33 \pm 31.80(21.57-43.09)$ & $16.34 \pm 13.98(12.45-20.24)$ & $0.002^{*}$ \\
Vitamin D [ng/mL] & $24.69 \pm 12.17(20.57-28.80)$ & $17.68 \pm 11.60(14.46-20.91)$ & $0.008^{*}$ \\
HbA ${ }_{1 C} \%$ & $6.37 \pm 0.45(6.22-6.53)$ & $9.94-2.37(9.28-10.60)$ & $0.000^{*}$ \\
Vitamin D Deficiency \% & $36.1(16)$ & $61.5(40)$ & $0.019^{*}$ \\
Vitamin D insufficiency \% & $30.6(14)$ & $26.9(17)$ & 0.71 \\
Hypovitaminosis D \% & $66.7(30)$ & $88.4(57)$ & $0.013^{*}$ \\
\hline
\end{tabular}

Categorical data are shown as \%; continuous variables are shown as mean \pm standard deviation. *Significant. TG — triglycerides, HDL — high density lipoproteins; $\mathrm{LDL}$ - low density lipoproteins; $\mathrm{HbA}_{1 \mathrm{C}}$ - glycosylated hemoglobin; HOMA-IR — homeostasis model of assessment-insulin resistance index; HOMA-B - homeostasis model of assessment-beta; $\mathrm{Cl}$ - confidence interval; $\mathrm{n}$ - number of patients

Table 3. Correlation of vitamin D with various parameters in cases and controls

\begin{tabular}{lcccc}
\hline Variables & \multicolumn{2}{c}{ Cases } & \multicolumn{2}{c}{ Control } \\
\cline { 2 - 5 } & Pearson & P value & Pearson & P value \\
\hline BMI & 0.171 & 0.111 & -0.163 & 0.253 \\
WHR & 0.049 & 0.648 & -0.047 & 0.741 \\
FPG & -0.019 & 0.857 & -0.402 & $0.003^{*}$ \\
Cholesterol & 0.035 & 0.747 & -0.235 & 0.097 \\
Triglycerides & -0.159 & 0.140 & -0.148 & 0.300 \\
HDL & -0.193 & 0.072 & 0.019 & 0.896 \\
LDL & 0.204 & 0.056 & 0.224 & 0.114 \\
HbA & -0.225 & $0.035^{*}$ & -0.373 & $0.007^{*}$ \\
FI & 0.250 & $0.019^{*}$ & 0.319 & $0.022^{*}$ \\
HOMA-IR & 0.172 & 0.109 & 0.280 & 0.056 \\
HOMA-B & 0.237 & $0.026^{*}$ & 0.370 & $0.008^{*}$ \\
\hline
\end{tabular}

*Significant. HDL - high density lipoproteins; LDL — low density lipoproteins; $\mathrm{HbA}_{1 \mathrm{C}}$ - glycosylated hemoglobin; $\mathrm{BMI}$ - body mass index; WHR — waist hip ratio; FPG — fasting plasma glucose; FI — fasting insulin; HOMA-IR - homeostasis model of assessment-insulin resistance index; HOMA-B - homeostasis model of assessment- beta

in diabetic group $(r=-0.019 ; P=0.857)$. We found a significant positive association between serum fasting insulin level and vitamin $D$ in both cases $(r=0.250$; $P=0.019)$ and controls $(r=0.319 ; P=0.022)$. Similarly there was a significant positive association between vitamin $D$ and HOMA-B in both cases $(r=0.237$; $P=0.026)$ and controls $(r=0.370 ; P=0.008)$, how- ever, there was no correlation between vitamin D status and HOMA-IR in diabetes patients $(r=0.172$; $P=0.109)$ as well as in healthy control $(r=0.280$; $P=0.056)$. We found a significant inverse correlation between serum 250HD level and $\mathrm{HbA}_{1 \mathrm{c}}$ in both cases $(r=-0.225 ; P=0.035)$ and controls $(r=-0.373$; $P=0.007$ ) (Figure 1, 2).

\section{Discussion}

Vitamin D deficiency is a global health problem affecting almost all the countries of the world including India, with studies estimating the community prevalence of $50 \%$ to $94 \%$ [12]. Similarly a very high prevalence of vitamin D inadequacy was demonstrated in apparently healthy, young, and non-pregnant adults of Kashmir region in northern India [13] aged 18-40 years. Of the 92 healthy natives including 64 men and 28 non-pregnant/non-lactating women, aged 18-40 years, $83 \%$ had VDD with $25 \%, 33 \%$, and $25 \%$ having mild, moderate, and severe deficiency, respectively. The presence of high prevalence of both VDD and T2DM in the Kashmir valley and evidence linking VDD with variety of chronic diseases including T2DM prompted us to take up this study to find the link between the two major health problems.

Insulin resistance and or action and impaired insulin secretion are the main significant factors involved in the pathogenesis of T2DM though other distinct pathophysiologic abnormalities commonly referred as 


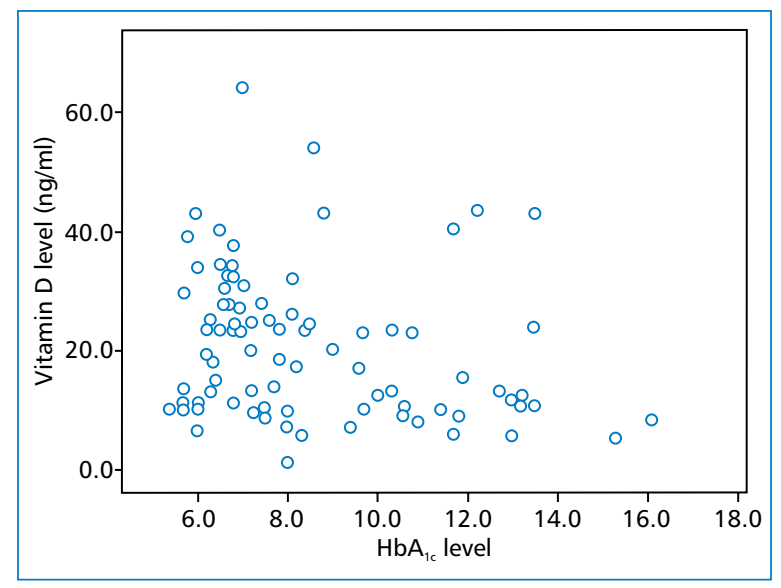

Figure 1. Scatter plot between vitamin $\mathrm{D}$ and $\mathrm{HbA}_{1 \mathrm{c}}$ of cases

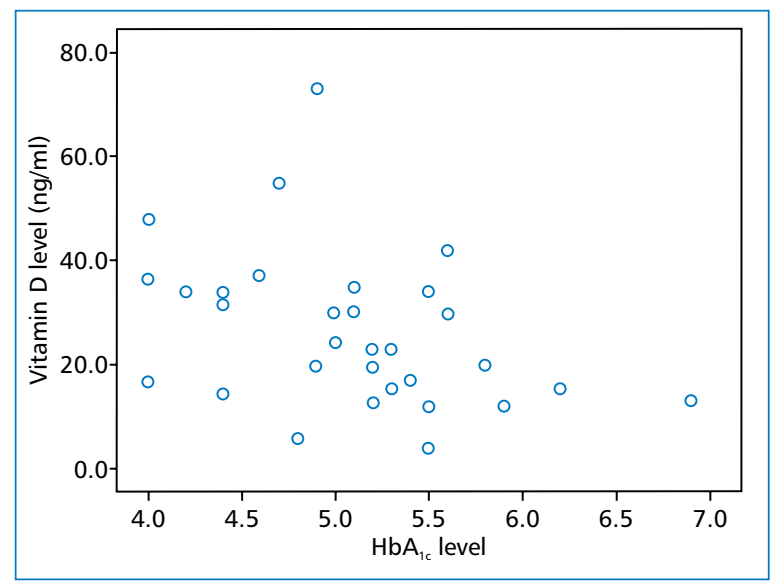

Figure 2. Scatter plot between vitamin $\mathrm{D}$ and $\mathrm{HbA}_{1 \mathrm{c}}$ in control

"Ominous Octet" have been associated with T2DM. Vitamin $D$ has been found to influence these mechanisms and has been suggested to play an important role in modulating impaired pancreatic beta cell function, insulin resistance and systemic inflammation, seen in patients with T2DM [14]. Vitamin D has been implicated to have beneficial effect on insulin sensitivity through various mechanisms including, directly acting on insulin receptors [15], thus improving glucose transport across the cells in the target tissues and by activating peroxisome proliferator activator receptor- $\delta$ thereby regulating fatty acid metabolism [16] in addition to affecting the calcium homeostasis [17] Similarly vitamin $D$ has been found to have beneficial effects on insulin release by acting directly on vitamin $\mathrm{D}$ receptor in $\beta$ cells and vitamin D-dependent calcium-binding proteins [18] and indirectly via regulation of calcium transport through $\beta$-cells [19].
The present study is the first study on the relationship between type $2 \mathrm{DM}$ and 250HD in the Kashmir valley of Northern India. In the current study, mean age of patients with T2DM and controls was $48.28 \pm$ 9.535 , and $48.12 \pm 9.354$ years respectively.

The prevalence of VDD and insufficiency in T2DM patients in the current study was $51.1 \%$ and $28.4 \%$ respectively, whereas the prevalence of VDD and vitamin $D$ insufficiency in healthy controls was $41.2 \%$ and $19.6 \%$ respectively. Despite the high prevalence of hypovitaminosis $\mathrm{D}(<30 \mathrm{ng} / \mathrm{mL})$ in the studied population it was significantly pronounced in patients with T2DM (79.5\%) compared to healthy controls (60.8\%). On further analysis it was found that VDD was more prevalent in diabetic patients with poor glycemic control compared to those with good glycemic control. The presence of comparatively higher prevalence of hypovitaminosis $D$ in diabetic patients in general and in patients with poor glycemic control in particular is in agreement with the results documented in previous studies from Asian countries [20-22].

The main source of Vitamin $D$ is skin exposure to ultraviolet $B$ radiation (UVB) from the sun however, dietary and supplemental intake, lifestyle and underlying health conditions also influence the vitamin $D$ status of the body [23]. The higher levels of VDD in patients of T2DM could be because of relatively limited sun exposure on account of limited physical activity and presence of obesity in diabetes in addition to impaired conversion of precursors of vitamin $D$ in liver and kidneys in the presence of liver disease and nephropathy. Large number of observational studies across the world have demonstrated an inverse association of serum levels of $25 \mathrm{OHD}$ and $\mathrm{HbA}_{1 \mathrm{c}}$ supporting a possible active role of VDD in pathogenesis of T2DM. NHANES analysis of 9,773 adults who participated in the 2003-2006 NHANES, found that serum 25OHD concentration was inversely associated with $\mathrm{HbA}_{1 \mathrm{c}}$ level in individuals 35-74 years old, but not among the younger or older adults [24]. Our study like other observational studies also demonstrated a significant inverse correlation between Vitamin $D$ levels and $\mathrm{HbA}_{1 \mathrm{c}}$ levels which is in agreement with results documented in the literature $[20,22,24,25]$. Patients with VDD have been found to have higher $\mathrm{HbA}_{1 c^{\prime}}$ a marker of prolonged glycemic control, however, some authors suggest that vitamin $D$ may be a marker of general health and its association with T2DM may be a coincidence [26]. Observational nature of these studies did not provide a conclusive evidence for any possible cause and effect relationship between VDD and type 2 diabetes mellitus. Despite sufficient evidence for possible association in observational studies, Interventional studies have been inconclusive 
to address the nature of relationship between the two. Lack of conclusive evidence of association between the two have given credence to the observation that a low serum $250 \mathrm{HD}$ level might be the result of poorer health or even worse metabolic control of diabetes.

One of the observations of our study was the inverse association of serum vitamin D levels with fasting plasma glucose in patients of T2DM; however the relation was not statistically significant. The reason for statistically insignificant relation for the cases could be the adequate treatment by oral anti-diabetic medications. This observation was consistent with results from a study by Kumar et al. who observed that vitamin D level was inversely related to fasting blood sugar in patients with T2DM [22]. We also found that the fasting plasma glucose levels of healthy controls had significant inverse relation with serum vitamin D levels. This is similar to the conclusion drawn from a meta-analysis which showed that there was an overall inverse association of vitamin D status and fasting plasma glucose in the non-diabetic population [22, 27]. This relationship of vitamin D with plasma glucose level suggested that hypovitaminosis $D$ is associated with increased risk of hyperglycemia both in diabetic and non-diabetic subjects. We found a significant positive association between serum fasting insulin level and vitamin $D$ in both cases and controls, which is similar to results demonstrated in an earlier study where authors concluded that vitamin $D$ is positively associated with insulin levels [28]. HOMA-B represents insulin secretory capacity of pancreatic beta cells and thus the higher the value the more the beta-cells have to secrete insulin to handle existing blood glucose level. VDD has been found to inhibit insulin secretion by modulating VDR on pancreatic beta cells. Our study demonstrated a significant positive association between vitamin $D$ levels and HOMA-B in both cases and controls thus highlighting the importance of vitamin $D$ in insulin secretion. In the current study we did not found any significant correlation between serum vitamin $D$ levels and HOMA-IR levels in both the control group and the diabetic patients. The lack of association between the vitamin D levels and HOMA-IR is consistent with the results demonstrated in earlier studies $[25,29,30]$.

\section{Limitations of the study}

The present study has several limitations. Observational nature of present study prevents us from making any conclusive observation as far as any cause and effect relationship between VDD and T2DM is concerned. The study sample was relatively too small to project the results to whole population to draw any conclusive inference.

\section{Summary and conclusion}

We conclude that the prevalence of hypovitaminosis $D$ is very common; however, in patients with T2DM, it is relatively more common compared to non-diabetics. We also found that there is an inverse relation between vitamin $\mathrm{D}$ and $\mathrm{HbA}_{1 \mathrm{c}}$ which is marker of prolonged glycemic status, thus highlighting the possible role of vitamin $\mathrm{D}$ in glycemic control $\left(\mathrm{HbA}_{1 \mathrm{c}}\right)$. On the basis of the findings in our study, we suggested, there should be a routine screening for vitamin $D$ levels in patients with diabetes and patients with diabetes should suplement vitamin D in their diet; a plausible way to mitigate the impact of VDD in the pathogeneses of T2DM. However, long term studies with a larger cohort, investigating the effect of supplementation of vitamin D on the incidence and glycemic control of T2DM can significantly help to drive a conclusive evidence linking those two.

\section{Acknowledgements}

We are thankful to all the participants for cooperation and providing all the information required for the study. We wish to sincerely thank Mr. Zahoor Ahmad, chief technologist from Deptt. of biochemistry for processing the samples utilized in the current study.

\section{Declaration of patient consent}

The authors certify that they have obtained all appropriate patient consent forms. The patients understand that their names and initials will not be published and due efforts will be made to conceal their identity.

\section{Conflict of interest}

None declared.

\section{REFERENCES}

1. Saeedi P, Petersohn I, Salpea P, et al. Global and regional diabetes prevalence estimates for 2019 and projections for 2030 and 2045: Results from the International Diabetes Federation Diabetes Atlas, 9 edition. Diabetes Res Clin Pract. 2019; 157: 107843, doi: 10.1016/j.diabres.2019.107843, indexed in Pubmed: 31518657.

2. Zargar AH, Khan AK, Masoodi SR, et al. Prevalence of type 2 diabetes mellitus and impaired glucose tolerance in the Kashmir Valley of the Indian subcontinent. Diabetes Res Clin Pract. 2000; 47(2): 135-146, doi: 10.1016/s0168-8227(99)00110-2, indexed in Pubmed: 10670914.

3. Dar IH, Dar SH, Bhat RA, et al. Prevalence of type 2 diabetes mellitus and its risk factors in the age group 40 years and above in the Kashmir valley of the Indian subcontinent. 2015; 16(3): 11.

4. Kharroubi AT, Darwish HM. Diabetes mellitus: The epidemic of the century. World J Diabetes. 2015; 6(6): 850-867, doi: 10.4239/ wjd.v6.i6.850, indexed in Pubmed: 26131326.

5. Liebl A, Khunti K, Orozco-Beltran D, et al. Health economic evaluation of type 2 diabetes mellitus: a clinical practice focused review. Clin Med Insights Endocrinol Diabetes. 2015; 8: 13-19, doi: 10.4137/CMED.S20906, indexed in Pubmed: 25861233.

6. Mitri J, Pittas AG. Vitamin D and diabetes. Endocrinol Metab Clin North Am. 2014; 43(1): 205-232, doi: 10.1016/j.ecl.2013.09.010, indexed in Pubmed: 24582099. 
7. Leung PoS. The potential protective action of vitamin D in hepatic insulin resistance and pancreatic islet dysfunction in type 2 diabetes mellitus. Nutrients. 2016; 8(3): 147, doi: 10.3390/ nu8030147, indexed in Pubmed: 26959059.

8. Palomer X, González-Clemente JM, Blanco-Vaca F, et al. Role of vitamin $D$ in the pathogenesis of type 2 diabetes mellitus. Diabetes Obes Metab. 2008; 10(3): 185-197, doi: 10.1111/j.14631326.2007.00710.x, indexed in Pubmed: 18269634.

9. Tai K, Need AG, Horowitz M, et al. Vitamin D, glucose, insulin, and insulin sensitivity. Nutrition. 2008; 24(3): 279-285, doi: 10.1016/j. nut.2007.11.006, indexed in Pubmed: 18187309.

10. Bland R, Markovic D, Hills CE, et al. Expression of 25-hydroxyvitamin D3-1alpha-hydroxylase in pancreatic islets. J Steroid Biochem Mol Biol. 2004; 89-90(1-5): 121-125, doi: 10.1016/j. jsbmb.2004.03.115, indexed in Pubmed: 15225758.

11. Oli JM, Adeyemo AA, Okafor GO, et al. Basal insulin resistance and secretion in Nigerians with type 2 diabetes mellitus. Metab Syndr Relat Disord. 2009; 7(6): 595-599, doi: 10.1089/met.2009.0002, indexed in Pubmed: 19900160.

12. Aparna $P$, Muthathal $S$, Nongkynrih $B$, et al. Vitamin D deficiency in India. J Family Med Prim Care. 2018; 7(2): 324-330, doi: 10.4103/ jfmpc.jfmpc_78_18, indexed in Pubmed: 30090772.

13. Zargar AH, Ahmad S, Masoodi SR, et al. Vitamin D status in apparently healthy adults in Kashmir Valley of Indian subcontinent. Postgrad Med J. 2007; 83(985): 713-716, doi: 10.1136/ pgmj.2007.059113, indexed in Pubmed: 17989271.

14. Pittas AG, Lau J, Hu FB, et al. The role of vitamin D and calcium in type 2 diabetes. A systematic review and meta-analysis. J Clin Endocrinol Metab. 2007; 92(6): 2017-2029, doi: 10.1210/jc.20070298, indexed in Pubmed: 17389701.

15. Maestro B, Campión J, Dávila N, et al. Stimulation by 1,25-dihydroxyvitamin D3 of insulin receptor expression and insulin responsiveness for glucose transport in U-937 human promonocytic cells. Endocr J. 2000; 47(4): 383-391, doi: 10.1507/endocrj.47.383, indexed in Pubmed: 11075718.

16. Dunlop TW, Väisänen S, Frank $C$, et al. The human peroxisome proliferator-activated receptor delta gene is a primary target of 1alpha,25-dihydroxyvitamin D3 and its nuclear receptor. J Mol Biol. 2005; 349(2): 248-260, doi: 10.1016/j.jmb.2005.03.060, indexed in Pubmed: 15890193.

17. Williams PF, Caterson ID, Cooney GJ, et al. High affinity insulin binding and insulin receptor-effector coupling: modulation by Ca2+. Cell Calcium. 1990; 11(8): 547-556, doi: 10.1016/01434160(90)90031-o, indexed in Pubmed: 1702365.

18. Johnson JA, Grande JP, Roche PC, et al. Immunohistochemical localization of the 1,25(OH)2D3 receptor and calbindin D28k in human and rat pancreas. Am J Physiol. 1994; 267(3 Pt 1):
E356-E360, doi: 10.1152/ajpendo.1994.267.3.E356, indexed in Pubmed: 7943215.

19. Sergeev IN, Rhoten WB. 1,25-Dihydroxyvitamin D3 evokes oscillations of intracellular calcium in a pancreatic beta-cell line. Endocrinology. 1995; 136(7): 2852-2861, doi: 10.1210/ endo.136.7.7789310, indexed in Pubmed: 7789310.

20. Iqbal K, Islam N, Mehboobali N, et al. Association of vitamin D deficiency with poor glycaemic control in diabetic patients. J Pak Med Assoc. 2016; 66(12): 1562-1565, indexed in Pubmed: 28179690.

21. Aljabri K. Study of vitamin D status and its correlation with glycated haemoglobinin type 2 diabetes mellitus. Journal of Obesity and Diabetes. 2019: 12-16, doi: 10.33805/2638-812x.111.

22. Kumar $H$, Singh BV, Meena BL, et al. Correlation of vitamin D level with glycemic control in type 2 diabetes mellitus. Sch J Appl Med Sci. 2015; 3(6): 2277.

23. Prentice A, Schoenmakers I, Jones KS, et al. Vitamin D deficiency and its health consequences in africa. Clin Rev Bone Miner Metab. 2009; 7: 94-106, doi: 10.1007/s12018-009-9038-6, indexed in Pubmed: 25110467.

24. Kositsawat J, Freeman VL, Gerber BS, et al. Association of A1C levels with vitamin D status in U.S. adults: data from the National Health and Nutrition Examination Survey. Diabetes Care. 2010; 33(6): 12361238, doi: 10.2337/dc09-2150, indexed in Pubmed: 20215453.

25. Chinedu A, Fasanmade OA, Coker $\mathrm{H}$, et al. Relationship between vitamin $D$ levels and glycaemic control in Type 2 diabetes mellitus patients in Lagos, Nigeria. Journal of Diabetology. 2017; 8(2): 32, doi: 10.4103/jod.jod_17_17.

26. Autier $P$, Mullie $P$, Macacu A, et al. Vitamin D status and ill health: a systematic review. Lancet Diabetes Endocrinol. 2014; 2(1): 76-89, doi: 10.1016/S2213-8587(13)70165-7, indexed in Pubmed: 24622671.

27. Rafiq S, Jeppesen PB. Is Hypovitaminosis D Related to Incidence of Type 2 Diabetes and High Fasting Glucose Level in Healthy Subjects: A Systematic Review and Meta-Analysis of Observational Studies. Nutrients. 2018; 10(1), doi: 10.3390/nu10010059, indexed in Pubmed: 29320437.

28. Chiu KC, Chu A, Go VL, et al. Hypovitaminosis D is associated with insulin resistance and beta cell dysfunction. Am J Clin Nutr. 2004; 79(5): 820-825, doi: 10.1093/ajen/79.5.820, indexed in Pubmed: 15113720.

29. Fondjo LA, Owiredu WK, Sakyi SA, et al. Vitamin D status and its association with insulin resistance among type 2 diabetics: A case -control study in Ghana. PLoS One. 2017; 12(4): e0175388, doi: 10.1371/journal.pone.0175388, indexed in Pubmed: 28423063.

30. Sheth JJ, Shah A, Sheth FJ, et al. Does vitamin D play a significant role in type 2 diabetes? BMC Endocr Disord. 2015; 15: 5, doi: 10.1186/s12902-015-0003-8, indexed in Pubmed: 25887335. 